\title{
Queer caboclo como possibilidade anticolonial: Algumas reflexões à guisa de provocação
}

\section{Estevão Rafael Fernandes}

Resumo: O objetivo deste texto é refletir sobre as interseções possíveis entre um pensamento queer descolonizado e aspectos como desenvolvimento, consumo, corporalidade e subjetividade. Busca-se desenvolver por meio da noção de decolonialidade, duas hipóteses: da necessidade de um queer anticolonial; e que o contexto atual de radicalização das técnicas de normalização esteja relacionado às relações de colonialidade. Dessa maneira, um pensamento queer caboclo refere-se não apenas a temas como sexualidades, mas, também, à raça, etnicidade, classe, trabalho e neoliberalismo, por exemplo.

Palavra-chave: Queer, colonialismo, colonialidade, Amazônia, queer caboclo.

Queer caboclo as an anticolonial possibility: Some reflections by way of provocation

Abstract: The objective of this text is to reflect on the possible intersections between a decolonized queer thought and aspects such as development, consumption, corporeality and subjectivity. It seeks to develop, from the notion of decoloniality, two hypotheses: the need for an anticolonial queer; and that the current context of radicalization of normalization techniques is related to the relations of coloniality. Thus, a queer caboclo thought refers not only to

1 Programa de Mestrado em Direitos Humanos e Desenvolvimento da Justiça da Universidade Federal de Rondônia (UNIR) - Porto Velho - Brasil - estevaofernandes@gmail.com 
themes such as sexualities, but also to race, ethnicity, class, work and neoliberalism, for example.

Keywords: Queer, colonialism, coloniality, Amazon, queer caboclo.

Uma primeira tentação ao escrever este ensaio é começa-lo com uma definição instrumental do que seja queer para, então, tentar encaixá-la na realidade amazônica. Em seguida, o próximo passo lógico seria escrever algo acerca do que vem a ser colonialismo, como ele se caracteriza em terras brasileiras - sobretudo nas amazônicas, ponto de partida deste texto - e de que forma esse queer vai de encontro aos discursos e práticas cada vez mais normalizados no Brasil de hoje - citando, evidentemente, várias autoras e autores conhecidos, buscando inflar e legitimar o texto com largas citações em inglês e francês. Essa seria uma escolha segura de desenvolvimento do texto, no melhor estilo escolar como bem se espera na academia.

No entanto, penso que as próximas páginas mereçam tomar caminhos teóricos e estilísticos mais ousados. O digo à luz não somente das autoras e autores que constituem este dossiê, mas diante do que essas pessoas escreveram - e tem escrito - não apenas aqui, na Contemporânea ${ }^{2}$, mas também ou em suas inúmeras apresentações em congressos, livros e em rodas de café país afora. Neste sentido, o grupo Quereres tem trazido à tona, ao longo de vários anos, discussões sobre subalternidade, colonialismo e sul-global para os estudos queer brasileiros.

Por outro lado, temos um outro grupo pensando questões referentes à sexualidade - ainda que não necessariamente dentro das mesmas chaves interpretativas queer - por meio de instituições amazônicas ou deslocadas dos eixos hegemônicos de produção de conhecimento no país. A esses, como fica claro na leitura de dossiês da Aceno (UFMT)3 e Amazônica (UFPA) ${ }^{4}$, como questões sobre sexualidades rurais, interioranas, sertanejas, quilombolas, indígenas e ribeirinhas passam a figurar no centro das preocupações em relação aos contextos sociais e históricos dessas coletividades. De uma forma interessante, parece que esses dois grupos dialogavam intensamente, sem necessariamente conversarem, diretamente, entre si. Este dossiê é um primeiro passo neste sentido.

\footnotetext{
2 Refiro-me, sobretudo, ao dossiê "Saberes Subalternos", organizado por Larissa Pelúcio na Contemporânea, v. 2, n. 2, publicada em 2012.

3 V. 3, n. 5, publicado em 2016.

4 V.8, n. 1, publicado também em 2016.
} 
Mas não é sobre isso que este artigo trata - para isso, teremos a Apresentação deste número. Este texto parte de uma preocupação evidente na leitura dessa produção, de uma escalada de medo e intolerância, homotransfobia e racismos, agressões e normalização de ataques reais e virtuais ao diferente e da necessidade de um contraponto político e teoricamente que lhe faça frente. Isso fica claro, por exemplo, na leitura do Manifesto queer caboclo, publicado por Fernandes e Gontijo (2017): o que podemos compreender sobre exploração sexual de crianças na periferia, sobre o genocídio da população negra e sobre racismo ambiental no Brasil com base no queer? Que novas possibilidades essas questões trazem para essa chave interpretativa? Penso que isso possa nos fornecer algumas pistas importantes, não apenas sobre essas questões, mas sobre o próprio estado da democracia no Brasil, nos tempos que atravessamos.

Minha opção ao escrever este ensaio não é, como disse anteriormente, começar pelo queer, mas pelo que entendo ser uma crítica colonial que nos leve a pensar desde ou sobre o queer. A ideia é pensar em como queerificar o pensamento pós-colonial e como descolonizar o queer, desde a realidade amazônica brasileira. De certa forma, o texto possui um caráter bem exploratório, posto que a interseção desses dois campos ainda é algo relativamente inexplorado no país, de tal maneira que meu propósito aqui é muito mais apontar caminhos do que, necessariamente, fechar questões. Deixo claro minha hipótese de que as chaves interpretativas queer sejam não apenas pós, mas anticoloniais - ou, pelo menos, decoloniais5. Contudo, como se verá, minha noção de um pós-colonialismo é um pouco mais radical do que aquela apresentada pela academia francófona e lusófona. Dessa maneira, algumas coisas são necessárias, a título de introdução, a quem tenta entender o que significa, neste texto, "pós-colonial".

Em primeiro lugar, que o "pós”, em “pós-colonial” não pressupõe, em princípio, que as relações coloniais tenham, ao fim e ao cabo, chegado a um termo juntamente com as relações burocrático-administrativas que vinculam, política e historicamente, metrópole e colônia. Desta maneira, algumas das críticas que são feitas ao pensamento pós-colonial por sugerir, justamente, que haja aí algum pressuposto de que o colonialismo tenha findado com as independências de Estados nacionais nas Américas, África, Ásia ou qualquer outro continente localizado fora da Europa Ocidental, perdem sentido.

5 Apesar de utilizar largamente textos de autoras e autores decoloniais nas próximas páginas, o "decolonial", aqui, não se refere a esse conjunto de teóricos (Anibal Quijano, Walter Mignolo, dentre outros) mas, sobretudo, à busca de um descolamento (ou desprendimento, ou delink, como veremos) das categorias de pensamento colonizadas no sentido de criticar o léxico colonial como única alternativa possível - inclusive para compreender os processos de racialização e subalternização intrínsecos à prática colonial. 
O "pós", em "pós-colonial", ao contrário, busca ter o sentido de um "além" do colonial, de suas margens, de suas fronteiras; algo que pode ser percebido para além das formas colocadas pela(s) metrópole(s) no tocante a como o(s) povo(s) colonizado(s) reconstrói(em) sua memória, seu imaginário, suas relações cotidianas, seus afetos, sua percepção de mundo e seu próprio lugar nesse mundo.

Na busca por este ver-além, o pós-colonial, muitas vezes, se mune de teorias e críticas tais como o marxismo, o feminismo, o pós-estruturalismo e muitas outras vertentes filosóficas e políticas, quase sempre no intuito de buscar um olhar e um posicionamento desde o qual e para o qual seu lugar de enunciação não seja, necessariamente, o de uma sujeição a um olhar-se eternamente pelo olhar de fora e de cima, mas da problematização constante dos espaços que lhes são reservados pelas grandes narrativas hegemônicas quase sempre um lugar subalterno e invisível. Temos aqui, como se vê, um primeiro ponto de contato possível com o pensamento queer, em cujas origens está um conjunto de autoras e autores bastante próximos, para dizer o mínimo (refiro-me sobretudo a Foucault e Derrida).

Assim, em segundo lugar, faz-se necessário compreender que, apesar de fazer largo uso desse conjunto de teorias e críticas, o pós-colonial - assim como o queer - não se confunde com nenhuma delas. Da mesma forma, não se trata aqui de tomar o pós-colonial como a negação das contribuições teóricas "ocidentais", tampouco de assumir que se trate de uma teoria pronta e acabada. De algum modo, trata-se de uma chave interpretativa que oferece um espaço de contestação, partindo de uma relação crítica às várias formas de dominação - política, econômica, intelectual etc. - impostas, historicamente, por um conjunto de dispositivos e instituições a coletivos e sujeitos moldados de modo se manterem sob domínio. Novamente, temos um ponto de encontro com as possibilidades queer.

Veremos, ao longo das próximas páginas, como o colonialismo consiste em relegar o colonizado a uma nota de rodapé de sua própria história, construindo sua existência sempre por meio da narrativa do colonizador. Nesse percurso, apresentaremos chaves interpretativas desde as quais o pós-colonial se torna um espaço de resistência ontológica possível e necessária às visões etno e euronorcêntricas, ao patriarcado, ao racismo e às várias formas de dominação sobre as quais se assentam as relações coloniais. De certa forma, por se tratar de um movimento de re(l)ação crítica às hierarquias que buscam internalizar no colonizado um complexo de hierarquias, o pós-colonial torna-se uma possibilidade contestatória. 


\section{Nem lá, nem cá: escadas rolantes e usinas}

O queer em geral se caracteriza, antes e sobretudo, por ser antinormativo. Por serem tantas as definições e as noções do que venha a ser queer, parto aqui de uma noção instrumental para efeitos deste ensaio. Para isso, parto de um exemplo pouco usual - mas do qual gosto muito, particularmente. Refiro-me a Humpty Dumpty, personagem de Alice através do espelho, de Lewis Carroll.

No capítulo 06 desse livro, Alice encontra Humpty Dumpty que, lá pelas tantas, tenta convencer Alice de que melhor que ganhar presentes de aniversário (que ocorrem em um só dia do ano), é ganhar presentes de "desaniversário", nos 364 dias restantes... Segue parte do diálogo:

e isso mostra que há trezentos e sessenta e quatro dias em que você poderia ganhar presentes de desaniversário..."

"Sem dúvida", disse Alice.

"E só um para ganhar presentes de aniversário, vê? É a glória para você!"

"Não sei o que quer dizer com 'glória", disse Alice.

Humpty Dumpty sorriu, desdenhoso.

"Claro que não sabe... até que eu lhe diga. Quero dizer 'é um belo e demolidor argumento para você!'”

"Mas 'glória’ não significa 'um belo e demolidor argumento", Alice objetou.

"Quando eu uso uma palavra", disse Humpty Dumpty num tom bastante desdenhoso, "ela significa exatamente o que quero que signifique: nem mais nem menos".

"A questão é", disse Alice, "se pode fazer as palavras significarem tantas coisas diferentes".

"A questão", disse Humpty Dumpty, "é saber quem manda — só isto".

Queer é, no fim das contas, saber quem manda. É enfrentar, política e epistemicamente, processos dentro dos quais, por meio dos quais, pelo e para os quais sexualidades, afetos e desejos se conectam com o Poder. É questionar a naturalização, os binarismos e desconstruir relações sociais que banalizam, cotidianamente, tais processos. Dessa maneira, o queer passa a falar de racismos tanto quanto de homotransfobia, fala de classe tanto quanto de feminismos, fala de pobreza e fome tanto quanto de misoginia pois, de várias maneiras, esses processos se entrecruzam.

De fato, o que chama a atenção no queer é sua perspectiva de demonstrar o caráter de invenção da própria matriz de gênero, verificando "os conflitos, as brechas, os interstícios, as fissuras e as disjunções que possibilitam que os 
sujeitos subvertam as normas de gênero" (Pereira, 2006:470). E essas brechas precisam dizer tanto sobre processos de colonização, exploração, colonialismo interno e exclusão social quanto de normatização e sexo, por exemplo. Trata-se de enfrentar vários processos de silenciamento buscando, saliento, expor suas estruturas. É impossível, por exemplo - e venho buscado demonstrar isso no que já escrevi sobre o assunto - separar raça, etnicidade, sexualidade, classe e colonização no Brasil.

Como aponta Miskolci, a teoria queer compreende "a sexualidade como um dispositivo histórico de poder que marca as sociedades ocidentais modernas e se caracteriza pela inserção do sexo em sistemas de unidade e regulação social" (2009:154). Trata-se de focar em processos, por meio da desestabilização de categorias como "sujeito", "identidade", "agência" e "identificação": Autores como Judith Butler, por exemplo, analisam o processo pelo qual o indivíduo vem a assumir sua posição como um sujeito: o sexo e o gênero são efeitos de instituições, discursos e práticas: mais que algo que somos, é algo que fazemos (Salih, 2012:22). Novamente: processos.

Não se trata mais - ao menos não, somente - de buscar compreender a aparentemente óbvia relação entre raça, classe e sexo. Aliás, os estudos de interseccionalidade estão aí, justamente mostrando que essa relação tão clara não possui nada de simples. O que propomos aqui - e digo nós, por compreender que as pessoas que compõem este dossiê compartilhem desta visão, direta ou indiretamente - é a compreensão de sexualização, racialização e colonização (em suas múltiplas faces: classe, trabalho, distribuição desigual de capital social e simbólico etc.) como partes intrínsecas da criação, manutenção e legitimação de uma ordem social como gramática moral.

Nesse sentido, sintetizando o argumento de Miskolci nesse texto (2009), não são os sujeitos que criam experiências, mas as experiências que criam sujeitos, sujeitos esses marcados por processos sociais que precisam ser reconstituídos, explicitados e analisados pelo autor, incluindo "a necessidade de reconstituir historicamente e analisar sociologicamente os processos normalizadores que produzem esses outros, sem os quais o hegemônico também não se constituiria nem manteria seu poder" (:174). Prossegue o autor mais à frente:

a teoria queer mostra que identidades são inscritas através de experiências culturalmente construídas em relações sociais, e o êxito de investigações que busquem articular estas esferas dependerá do desenvolvimento de metodologias que não apenas permitam estudar cada um dos componentes do processo social de constituição das identidades, mas, sobretudo, analisem 
as interdependências entre categorias, de forma que não resultem na soma de opressões (:176).

Se a teoria trata, como diz o autor das linhas anteriores em seu texto, da "desconstrução da ontologia social", mais do que dicotomias homo/hétero cabe-nos ter em mente questionar os vários processos e espaços de poder que situam as diferentes perspectivas e práticas discursivas desses sujeitos.

De certa forma, o pós-colonial e o queer confluem, ao partirem de lugares nos quais é possível uma contranarrativa fora das categorias impostas histórica, social e epistemicamente, na, pela e para a manutenção das relações coloniais. Esse lugar possui vários nomes, dependendo do conjunto de autores aos quais podemos recorrer, mas a ideia é de uma margem, um local onde haja a possibilidade de uma existência do "eu" por meio do qual seu sotaque, sua língua, sua cor, seus afetos, suas referências, não sejam "as" erradas. O exemplo mais claro dessa margem é, penso, a noção de "Fronteira", desenvolvida por Glória Anzaldúa em seu clássico Borderlands/La Frontera: The New Mestiza (1987). Essas chaves interpretativas existem, por assim dizer, para dar vez e voz aos sujeitos que não se sentem incluídos ou representados nas grandes narrativas, sem necessariamente amarrá-los a outras categorias, estáveis. Trata-se de tirar "quem manda" do lugar de enunciação privilegiado a fim de desvelar esses privilégios e, assim, contrapô-los.

Como indicamos anteriormente, o pós-colonial é o espaço a ser ocupado pelo colonizado que não seja o de uma nota de rodapé de sua própria história, culpabilizado eternamente por seus próprios aparentes fracassos na tentativa de se enquadrar no modelo de modernidade liberal ocidental, nos padrões, no imaginário autoimagético do colonizador. Desta forma, oferece um lugar de contestação, reorientação e transformação à lógica da exploração, subordinação e invisibilidade. $\mathrm{O}$ mesmo pode ser dito, mutatis mutandi, a respeito do queer. Somente se pode considerar um pensamento como antinormatizador quando ele se contrapõe às questões de sexualidades, gênero, afeto e desejo; mas também põe em xeque divisões de classe, exploração, autoritarismo e exploração.

Novamente, é importante que se diga, aqui, que esse pós-colonial não é nem uma renúncia ou negação do ocidente, bem como um conjunto de teorias que se encontre em um passado histórico, morto e enterrado: é um olhar desde as margens e fronteiras, não pensando as periferias como sublugares, mas pensando uma outra noção de lugar, de fala, de pensar, de ser - novamente, paralelos com o queer são óbvios.

Uma forma bastante interessante de pensarmos as relações pós-coloniais é como um feixe de relações - políticas, ontológicas, sociais... - emaranhadas 
internamente, funcionando estruturalmente em conjunto, ainda que possam ser enxergadas, vez ou outra, por meio de suas partes. Explico isso de forma simples neste texto, com base em um exemplo cotidiano.

No momento em que escrevo estas palavras, encontro-me em um centro de compras na cidade de Porto Velho, localizada na Amazônia brasileira, relativamente próximo da fronteira com a Bolívia e, um pouco mais além, com o Peru. Cortando a cidade, um dos tributários meridionais do rio Amazonas, chamado rio Madeira.

Há alguns anos, em meio a um conjunto de políticas públicas de cunho desenvolvimentista, denominado pelo Governo Federal brasileiro de "Plano de Aceleração do Crescimento", resolveu-se construir, ao lado desta cidade, duas usinas hidrelétricas: Santo Antônio e Jirau. Um dos resultados desses empreendimentos foi o acelerado crescimento de Porto Velho e das pequenas cidades vizinhas: a população, então de duzentos mil habitantes, hoje beira o meio milhão de pessoas. Esse boom populacional não veio, infelizmente, acompanhado do devido planejamento em termos de políticas públicas, agravando problemas na área de saneamento básico, educação, transporte, segurança e infraestrutura. Como resultado, restaram diversos "monumentos ao progresso", sobretudo obras abandonadas aqui ou ali. Contudo, quero me prender aqui a um desses monumentos, localizado a poucos metros do lugar de onde escrevo: as escadas rolantes deste shopping center.

As pessoas não pensam muito em escadas rolantes e, sendo bem sincero, nem eu pensava. A mesma coisa com relação a centros de compras: em qualquer cidade de médio porte do mundo, o mesmo modelo: as mesmas lanchonetes de fast food, os mesmos barulhos, cheiros, cinemas onde passam os mesmos filmes e, claro, escadas rolantes. Acontece que, na Porto Velho da primeira década deste século, não havia escadas rolantes. Nem shopping centers. Nem redes de fast food americanas servindo seus "bigqualquercoisa". Na inauguração deste espaço, em 2008, foram chamados socorristas e bombeiros para auxiliarem as pessoas a utilizarem as escadas rolantes - conta-se que eram quatro por escada: dois na subida, dois na descida.

Tendo sido inaugurado no final de outubro daquele ano, no meio de um ambiente de empolgação pela chegada, afinal, do "progresso", logo as pessoas vinham de todo o sul amazônico para realizar suas compras de natal, tirar fotos da decoração natalina, das vitrines e, claro, das escadas rolantes. Ainda hoje, vários anos após a inauguração, é possível ver pessoas lutando contra a escada, a fim de se equilibrarem, sendo já alvo de comentários e risadas discretas (ou nem tanto). Das várias análises e digressões possíveis sobre essa narrativa, opto 
por privilegiar, aqui, uma chave de interpretação muito específica, tomando a representação que esses sujeitos têm da escada, mais do que a escada em si, como uma das margens do sistema colonial. Abramos aqui um parênteses para oferecer algumas chaves conceituais que podem nos ajudar a compreender em que ponto pretendo chegar. Ao final do texto, voltaremos às escadas.

\section{Outras formas de apre[e]nder/ser/estar no mundo}

Conforme uma das vertentes do pensamento pós-colonial latino-americano, conhecida como crítica decolonial (cf. as referências deste texto, para alguns textos introdutórios a essa noção), vemos que foram criadas identidades sociais baseadas na raça no decorrer da expansão colonial, servindo como base para a distribuição de trabalho e, por consequência, da exploração de mão de obra, do controle das subjetividades, afetos, conhecimentos etc. Assim, a cada grupo de pessoas racialmente classificadas equivalia uma forma de trabalho, de tal maneira que o controle dessa força de trabalho e desse grupo de pessoas passou a entrelaçar-se, criando uma nova forma de dominação baseada na raça. Repito: neste sentido, raça não é algo associado à cor da pele, mas a uma certa forma de classificação pensada com referência em determinado padrão de humanidade. Tenho consciência de que a colonialidade, como matriz de pensamento, possui vários problemas, tais como uma visão demasiadamente ampla de processos históricos e, talvez por conta disso mesmo, pouca atenção às formas empíricas por meio das quais esses processos ocorreram. Contudo, penso ser válido o pensamento de que o conceito de raça funda a visão euronorcêntrica de modernidade que se deu descobrimento das Américas.

Contudo, penso que esse momento também consolidou uma gramática moral que justificou não apenas a conquista do continente recém-descoberto, mas também a intensificação da vigilância sobre a esfera mais íntima - sexual, inclusive - dos súditos das coroas ibéricas - e o digo levando em conta dois fatores: a figura do padroado em Portugal e Espanha e o papel da igreja católica na consolidação desses Estados.

Dessa maneira, pensando com base nos pressupostos aristotélicos e tomistas que motivaram os primeiros passos da colonização da América, o padrão desejado era o homem católico europeu que praticava sexo com sua esposa para fins de reprodução. O que escapava a este padrão era classificado e hierarquizado como inferior, de modo que a categoria "europeu" passou a ser relevante como forma de classificação social e marcador de desigualdade, surgindo como contraponto aos "negros" (expressão que também designava os indígenas no 
Século XVI), às mulheres, e, no caso específico da América, aos selvagens, antropófagos, nus, ateus, sodomitas, idólatras... povos sem Fé, Lei, ou Rei. Foucault, com base em Hobbes e outros autores europeus irá demonstrar como, aos poucos, o Estado Moderno Europeu foi desenvolvendo formas de controle sobre os indivíduos.

Entretanto, não estamos falando da Europa, mas de seus apêndices coloniais (ie, nós). Assim, não há identidade possível fora do padrão de poder imposto ao longo do processo de colonização e, uma vez que tais relações de colonialidade persistem, perduram tais identidades. É possível transitar entre elas, como propõem os pós-estruturalistas? Possivelmente. Contudo, tais identidades ${ }^{6}$, mesmo $^{2}$ que em trânsito, seguem conduzindo a uma posição de subalternidade e deixando claro que o padrão de distribuição e usufruto do poder segue inexoravelmente. Como uma face de Jano, vislumbra-se o padrão de poder que marca o saber, o ser e o conhecer da América desde seu nascimento, mas mesmo o olhar de Jano tem seus pontos cegos e é dentro destes pontos cegos que opera a retórica decolonial enquanto estratégia emancipatória epistemopolítica.

Exemplos de outras formas de conhecer/saber/ser/estar-no-mundo são facilmente encontráveis, não apenas em comunidades "tradicionais" mas em outras coletividades. A questão é que todos os grupos que não se adequam ao modelo de conhecimento moderno/ euronorcêntrico são vistos como modos "alternativos" de conhecer, como se houvesse o "conhecimento global" (baseado na separação entre sujeito e objeto) e aqueles reduzidos a pecha de "tradicionais": os "saberes locais".

\section{Uma pequena pausa}

Nesse sentido, temos alguns desafios e perspectivas pela frente, em especial a necessidade de se desconstruir o desenho epistemológico hegemônico, por estar construído sobre a falsa noção de neutralidade, universalidade e atrelado ao modelo racional baseado na modernidade/euronorcentrismo.

6 Particularmente, estou cada vez mais convencido de que identidades fixas, vistas isoladamente ("negro", "mulher", "homossexual") correm o risco de ser essencializadas, e caírem em um discurso vazio de si e para si. Em vez disso, proponho que seja privilegiado o entrecruzamento dessas várias categorias em sua relação com o Estado e/ou com o poder estabelecido. A questão passa a ser, assim, como as várias instâncias de poder mantêm esses sujeitos submissos e invisíveis, mais do que, novamente, essencializá-las partindo justamente das categorias criadas e mantidas pelo colonizador. É necessário que se compreenda esse sistema de representações dentro de uma dinâmica discursiva, mais do que por egotrips estanques autorrepresentadas. 
Um sujeito epistêmico nestes termos assume (inadvertidamente, talvez) uma perspectiva de conhecimento moldada por meio das relações de colonialidade, contribuindo assim para sua manutenção. Nesse sentido, o pensar deve passar transversalmente pelo exercício de contínua vigilância e autocrítica epistêmica: é possível agir fora do modelo universalista, moderno, europeu de conhecimento? A história do pensamento social da forma como é ensinada hoje permite traçar uma genealogia direta entre a Grécia Clássica e os pensadores Modernos - como se houvesse apenas um percurso possível ao pensamento e o racionalismo moderno ocidental fosse a única maneira viável e legítima de se constituir o saber. Assim, há um continuum entre o mundo Helenístico, o Império Romano, o Renascimento e a Europa Moderna, como se (a) fosse um percurso retilíneo, uniforme e o mundo euronorcêntrico contemporâneo fosse a finalidade última de todos os povos (resultante da retórica da Modernidade); e/ou (b) não fosse possível um pensamento fora dessa noção de paradigma. Novamente, não se propõe aqui (e espero ter deixado isso suficientemente claro) a abnegação ao pensamento clássico ou dos filósofos europeus; o problema é apresentar-se tal sistema de pensamento como modelo, e fazê-lo de forma acrítica. Não proponho simplesmente que hajam apenas outros pensamentos possíveis, mas outros sistemas de pensamento que nos impõem conceitos-outros de epistemes. Assim, a questão passa a ser a reflexão crítica sobre o papel ocupado por intelectuais indígenas, afro-latinos, feministas, queer etc., nos livros e nas discussões que temos desenvolvido. De onde vem os conceitos que utilizamos, qual seu lugar de enunciação e em que medida se inserem em um padrão de poder moderno/colonial?

De que maneiras essas formas-outras de ser/estar no mundo nos impelem a compreender e superar, política e epistemologicamente, nossas próprias práticas e lugares de enunciação? Trata-se mormente de um exercício de interpenetração no mundo, diferentemente do olhar hegemômico, que o interpreta. $\mathrm{Na}$ primeira perspectiva, conhecer e ser são processos tomados transversalmente e de modo concomitante ao mundo: trata-se de perceber o mundo por tomar parte nele; na segunda, o sujeito cognoscente, neutro e racional, separa-se de seu "objeto". O queer caboclo é, certamente, um exemplo da primeira forma, desde a qual o pensamento é uma forma de intervenção política, e o é não apenas nos afetos, desejos e corpos, mas nas zonas, bregas e esquinas, tanto quanto nas dragas de garimpo, nas paradas de caminhão, no risca faca, no condomínio de luxo e no banco de trás das caminhonetes dos agroboys. Sobre isso não nos falam os franceses, nem os ingleses e, muitas vezes, nem mesmo os paulistas ou manauaras. E é nessa zona obscura que o anticolonialismo queer amazônico, sertanejo, favelado, periférico, subalternizado e invisibilizado existe. 
Tais perspectivas foram racializadas e subalternizadas à medida em que essas coletividades-outras foram sendo coisificadas. A senzala, o quilombo, o aldeamento, a beira do rio, a favela, a aldeia indígena, a fila do hospital, o baile funk, o campo de futebol na várzea, a periferia,... são loci de enunciação e de produção de epistemes e que dificilmente podem ser compreendidas plenamente se encapsuladas nas categorias de conhecimento universais/neutras/ euronorcêntricas/modernas.

Mais que nunca, diferença e desigualdade se confluem de forma mais ampla e irrestrita no sistema-mundo, desde uma perspectiva em cuja base reside um padrão moral historicamente constituído. Não há, no fim e ao cabo, qualquer novidade, do ponto de vista estrutural, nos processos narrados até aqui. Minha hipótese é a de que o atual momento (de trumpbolsonarismo, crises de refugiados, recrudescimento dos nacionalismos e dos conservadorismos) é, em alguma medida, uma radicalização das relações de colonialidade, necessárias para um reenquadramento das formas de exploração dos quatro níveis apontados por Mignolo e Tlostanova (2008) - Econômico, da Autoridade, das Sexualidades e do conhecimento e da subjetividade - para a manutenção das relações de poder no âmbito do capitalismo internacional, em especial em um capitalismo em crise após 2007/08.

O que se tem hoje é, justamente, a radicalização dos desenhos inventados pelo Ocidente: 1. A própria noção de ocidente; 2 . A perspectiva desde a qual o não ocidente colonizado se enxergue como ocidente (ie branco, hétero, cis, cristão etc.), impondo-se um padrão moral, econômico, simbólico, subjetivo etc. tal qual ocidente fosse, invisibilizando - e inviabilizando - visões outras de mundo; e 3. A crença de que o polo "ativo" (isto é, moderno, dinâmico etc.) seja o "ocidente", inclusive impondo-se a visão de que "a história" tenha se dado desde a Europa para o "resto" do mundo, como nas Cruzadas e/ou nos Descobrimentos.

O ponto a ser defendido aqui é, justamente, o de uma radicalidade-outra, desde a qual esta perspectiva deve ser reposicionada e descentrada, sobretudo desde a necessidade da consolidação de um ferramental epistemopolítico que se proponha - e que nos possibilite - contrapor essa lógica (e essa própria noção de "Lógica", como única possibilidade de experimentação do mundo) assumindo, afinal, que não somos ocidentais - aliás, fique claro desde já, para o Ocidente, a América Latina faz parte de um conjunto de países "alinhados" com o Ocidente, restritos à sua zona de influência.

Este texto é, de todas as formas, um experimento. Como disse, não se trata aqui de apontar respostas para as problemáticas apresentadas, mas de provocar novas perguntas. Parte das ciências sociais no país tem caminhado cada vez 
mais a um ensimesmamento, talvez por conta do ritmo de produção imposto pelas agências de fomento e de avaliação, talvez pelo esgotamento de paradigmas que viessem a atualizar as inquietações que tínhamos nas perspectivas críticas, marxistas de diversas tendências e pós-estruturais, dentre outras; talvez por decorrência das próprias disputas internas no campo das ciências sociais; talvez por não nos percebermos como latino-americanos, buscando sempre emular as respostas que a academia euronorcêntrica constrói em torno de seus problemas?

Esse processo, ainda, perpassa e corrobora (e é corroborado) os processos de expansão colonial de línguas e memórias, tornando possível apenas uma forma de existir histórica e socialmente. A única forma legítima de se compreender a si mesmo é deslocando-se para um espaço impessoal, assexuado, atemporal e externo. Nessa contradição sustentam-se as bases epistêmicas desse saber moderno e objetivo, bem como a racionalidade intrínseca aos processos de colonização do mundo da vida (lebenswelt $)^{8}$, entendendo-se, uma vez mais, tais processos como não necessariamente findos com a independência política entre duas unidades distintas, mas sim enquanto processos de suplantação de outras formas de ser, saber, sentir e existir. Dessa forma, esse giro epistêmico se caracterizaria por deslocar esse sujeito epistêmico desse centro fixo e artificialmente sobreposto9.

Uma vez mais, vale a pena ressaltar que a forma como isso se dá não é pela pura e simples negação dos processos de colonização ou do conhecimento gerado por meio desses contextos e relações. Seria, no mínimo, ingênuo assumir que autores como Marx, Weber, Foucault, Bourdieu e Elias, por exemplo, não trariam contribuições claras para se pensar a realidade social latino-americana pelo simples fato de serem europeus (afinal, a culpa não é deles...); mas é igualmente discutível, à luz desta perspectiva, a postura adotada por alguns colegas da academia de se comportarem como se vivessem no Quartier Latin ou no Greenwich Village, alheios ao que se passa fora de seus gabinetes. Decolonizar o pensamento é visibilizar as formas de pensamento, memórias, saberes, línguas e subjetividades racializadas e subalternizadas.

A ciência moderna reflete, como regra, tais contradições, havendo todo um conjunto de saberes que foram subalternizados e invisibilizados frutos de um processo de normalização do conhecimento com base pressupostos políticos, ideológicos, racializados e que perpassam toda uma série de relações que 
transcendem a academia em sua gênese e manutenção: os saberes fronteiriços parecem qualquer outra coisa, que não outras relações e processos de conhecimento-outros. Nesse sentido, essa zona de interstícios de conhecimentos foi gradativamente suprimida em nome de uma suposta neutralidade axiológica e heurística originada, em larga medida, de processos históricos de racialização, proletarização, colonialidade, entre outros, dada como única alternativa possível.

Os processos de avaliação, políticas públicas, distribuição de recursos (financeiros, simbólicos, humanos etc.) para as zonas periféricas de produção do conhecimento têm tendido cada vez mais à normalização e diante de padrões que apenas replicam, nessas zonas, as assimetrias de poder que historicamente marcam as microrrelações cotidianas na América Latina. Tem-se, assim, um colonialismo epistêmico interno, que obscurece toda uma possibilidade de conhecimentos possível, existentes no âmbito da "ferida colonial" (para usar uma expressão bastante utilizada por Walter Mignolo (1999), a partir dos escritos de Gloria Anzaldúa ${ }^{10}$ ). Trata-se, como sintetiza esse mesmo autor, não da substituição de um novo paradigma, nos termos de Kuhn (1997), mas do surgimento de paradigmas-outros: mais que outra epistemologia, uma episteme-outra.

Aliás, neste sentido, vale um relato pessoal: em minha própria pesquisa sobre homossexualidade indígena ${ }^{11}$, tenho tido sérias dificuldades em demonstrar que as críticas desses indígenas provêm de fraturas resultantes não apenas das ações normalizadoras às quais foram sujeitos desde o início da colonização, mas também do modo pelo qual nossa ontologia (moderna, racional e objetiva) se apropria dessas possibilidades-outras de ser para adequá-las às nossas.

O queer indígena fornece uma crítica anticolonial calcada numa perspectiva pan-indígena, enquanto crítica ao processo colonial como um todo, sem particularismos. A meu ver, a força dessa perspectiva reside em sua possibilidade de se retirar os indígenas da condição de sujeitos de pesquisa, reconhecendo seu papel de agentes e produtores de conhecimento sobre o mundo. Neste sentido, se utilizarmos o queer indígena como possibilidade epistêmica, teremos a possibilidade de realizar um giro epistêmico por meio do qual ampliam-se nossas concepções não apenas sobre sexualidade e etnologia indígena, mas sobretudo sobre epistemologia, colonização, contato interétnico, raça etc. O que as críticas queer indígenas no Brasil, vistas como pensamento anticolonial, nos permitem acessar são justamente as zonas obscuras criadas pela colonização; zonas que as Ciências Sociais, como regra, historicamente não acessaram.

$10 \quad$ Em especial Anzaldúa, 1987.

11 Cf. Fernandes, 2015. 
As políticas de miscigenação forçada, a imposição de nomes "de branco" aos indígenas, a divisão no trabalho e no espaço escolar, os cortes de cabelo, a distribuição de roupas e outras tantas ações nas quais historicamente a ação indigenista da sociedade envolvente se pauta/pautou são baseadas em - ao mesmo tempo em que sustentam - um sistema discursivo de sexualidade do colonizador. O horizonte que se abre para pesquisadoras interessados em trabalhar tais questões no Brasil fornece a possibilidade de efetuar uma crítica não apenas do processo colonizador em si, mas também de toda a nuvem discursiva que o legitimou e legitima. Aliás, esse é um ponto importantíssimo. O colonialismo opera nas brincadeiras, no preconceito, nas agressões e nas mortes que, ainda hoje, indígenas LGBTQ+ sofrem dentro e fora de suas aldeias.

Dessa maneira, minha alternativa acabou sendo trabalhar a "homossexualidade indígena" de forma não particularista - evitando questões do tipo "que nome a etnia tal dá para gays e lésbicas?" - por ter claro que perguntas desta ordem são portadoras de uma perspectiva completamente alheia a dos povos indígenas. Como proceder quando os indígenas simplesmente não identificam nas práticas homossexuais algo dotado de importância suficiente para ser nominado? E no caso da masturbação entre homens, isso é homossexualidade? No caso do sexo anal eventual em uma caçada? Exemplos seriam legião, aqui.

Dessa forma, minha saída acabou sendo compreender a "homossexualidade indígena" não com base em práticas sexuais, ou orientação sexual, mas como fenômeno político: segundo penso, quando o indígena se percebe como "homossexual" ou "gay" é porque a carga pejorativa de preconceitos vindos do processo colonial o alcançaram. Neste caso, é frequente no Brasil o caso de indígenas chamados de "veado" em suas respectivas línguas - a quem não sabe, veado é a forma pejorativa, em terras brasileiras, para referir-se a homens gays. Sendo assim, temos um campo de possibilidades epistêmicas para desconstruir categorias bastante arraigadas nas Ciências Sociais, deixando de reproduzir explicações e lógicas que nem sempre trazem à tona a arbitrariedade por meio da qual nossas categorias analíticas são construídas e mantidas.

Chamar esses processos de gênero, sexualidade, corporalidade ou pessoa, restringindo-se a ajustá-los às nossas caixas conceituais, sem levar em conta os processos pelos quais esses grupos foram (e são) invisibilizados é submetê-los, uma vez mais, a outras formas de violência (política, epistêmica, cultural, por exemplo). Em larga medida, ao proceder de forma inadvertida de modo a encapsular essas formas-outras de existência (às vezes com as melhores intenções, e providos com um vasto arcabouço teórico) não nos damos conta de que 
reproduzimos e reforçamos estruturas coloniais subjacentes às formas pelas quais tais coletividades foram (e são) subalternizadas.

Sempre que posso deixo claro - e este texto é mais uma oportunidade disso - que esses processos não se restringem apenas aos povos indígenas do país, mas a toda população que não se enquadre na categoria "moderno": eis o claro ponto de interseção entre as críticas ao processo colonial e as chaves interpretativas queer: ambas se contrapõem a categorias dadas, buscando compreendê-las dentro de estruturas de poder mais amplas, histórica, social e politicamente constituídas.

\section{Fechando algumas questões, antes de voltarmos à escada}

Penso que haja, nos vários autores mencionados ao longo deste trabalho, claros pontos de contato que nos permitiriam avançar em diversas direções. Parto, contudo, em um caminho específico, por meio de um questionamento subjacente a diversas questões apontadas até aqui: é possível trabalhar a colonização partindo da mesma matriz de pensamento ocidental, moderna e eurocentrada da qual raça, gênero, ciência e normalização, por exemplo são parte? Há como se trabalhar estas questões escapando das armadilhas imbricadas em cada um destes conceitos e ideias?

Penso que uma resposta para este dilema seja buscar o que Mignolo (2010) entende por desprendimento (de-link), ao problematizar as implicações das formas como o saber é construído e legitimado dentro da modernidade/colonialidade. Nosso conhecimento fundamenta-se em uma perspectiva de neutralidade axiológica que se baseia ela mesma em um ideal de modernidade euronorcêntrica que se situa - e se legitima - no pressuposto de ser ontologicamente distinta (e superior) às formas como coletividades-outras constroem seu conhecimento e suas formas de estar/ser no mundo. Como Mignolo assinala, o controle da economia e da autoridade depende diretamente do controle do conhecer (epistemologia), do compreender (hermenêutica) e do sentir (æsthesis). No meta-relato colonial há uma linearidade e uma teleologia que não apenas invisibiliza outras formas de conhecimento, compreensão e sentido; mas toma para si, como já apontamos, uma narrativa heroica por salvar os "outros" da inferioridade técnica, econômica, política e ontológica. Há, como demonstra Mignolo (:13), um processo de "inversão do reconhecimento": enquanto, a partir do Século XVI, otomanos, russos, incas e chineses começam a reconhecer as línguas ocidentais e suas categorias de conhecimento, a filosofia e economia políticas se expandiam sem reconhecê-las "como iguais no 
jogo". Cabia a elas o papel passivo de reconhecerem sem serem reconhecidas. Desta forma, a colonização do conhecimento torna-se parte importante na dinâmica colonial sendo que, como apontado aqui, descolonizar o conhecimento torna-se tarefa imprescindível.

Tal perspectiva, programaticamente, pode ser sintetizada na passagem de Quijano, a seguir:

Em primeiro lugar, a descolonização epistemológica, em seguida, afaste-se para uma nova comunicação intercultural, a uma troca de experiências e significados, como a base de uma outra racionalidade que possa reivindicar, com legitimidade, alguma universalidade. Nada menos racional, finalmente, que alegar que a visão de mundo específica de determinado grupo étnico se impõe como racionalidade universal, ainda que tal etnia se chame Europa ocidental. Porque isso, na verdade, é buscar para um provincianismo o título de universalidade ${ }^{12}$ (Quijano, 1992: 447, apud Mignolo, 2010: 17).

Como indica Mignolo (loc. cit.), o desprendimento é o ponto de partida para o giro decolonial, a a afastar a ideia "linear da história imperial, eurocentrada, na medida em que se concebe o devir histórico em sua multiplicidade, entrelaçado por relações coloniais de poder que deverão ser descolonizadas em vista da realização da pluriversalidade como projeto universal”.

Em outro texto, Mignolo sintetiza em que medida o pensamento decolonial é epistêmico, ao se desvincular:

Dos fundamentos genuínos dos conceitos ocidentais e da acumulação de conhecimento. Por desvinculamento epistêmico não quero dizer abandono ou ignorância do que já foi institucionalizado por todo o planeta (por exemplo, veja o que acontece agora nas universidades chinesas e na institucionalização do conhecimento). [...] Há muitas opções além da bolha do Show de Truman. E é dessas opções que emergiu o pensamento descolonial. Pensamento descolonial significa também o fazer descolonial, já que a distinção moderna entre teoria e prática não se aplica quando você entra no campo do pensamento da fronteira e nos projetos descoloniais; quando você entra no campo do quichua e quechua, aymara e tojolabal, árabe e bengali, etc. categorias de pensamento confrontadas, claro, com a expansão implacável dos fundamentos do conhecimento do Ocidente (ou seja latim, grego, etc.), digamos, epistemologia. Uma das realizações da razão imperial 
foi a de afirmar-se como uma identidade superior ao construir construtos inferiores (raciais, nacionais, religiosos, sexuais, de gênero), e de expeli-los para fora da esfera normativa do "real" (Mignolo, 2008: 290-291).

Desta forma, o autor nos chama a atenção para os riscos de se buscar um lugar de enunciação situado na colonialidade para denunciar a modernidade, sendo necessária uma pluriversalidade de projetos por meio de histórias locais que pensem, criticamente - e fora "da bolha" - a expansão ocidental/moderna/ colonial. Trata-se não da rejeição da produção euronorcêntrica, mas de se levar em conta a produção, práticas, teorias, experiências, conceitos e pensamentos produzidos nas periferias, de modo a se questionar "o universalismo etnocêntrico, o eurocentrismo teórico, o nacionalismo metodológico, o positivismo epistemológico e o neoliberalismo científico", como bem aponta Ballestrin (2013: 109), em sua análise sobre as Ciências Sociais e as Teorias e Epistemologias do Sul-Global.

Olhar decolonialmente implica, assim, em se descentrar o olhar, buscando justamente iluminar as fraturas do processo colonial, ainda em curso. Isso impõe alguns desafios de ordem prática - e utilizo aqui o caso brasileiro para expor, ainda que de forma bastante preliminar, alguns deles.

O primeiro é decolonizar o imaginário e a memória (Pérez, 1999), pondo em xeque a historicidade tradicional ensinada desde cedo, contada por meio de ciclos e focando as regiões nas quais esses ciclos se localizaram, privilegiando quase sempre o olhar das elites metropolitanas e/ou [tras-]nacionais e o poder exercido sobre seus subalternizados: um processo construído como unilinear e voltado ora para os interesses da metrópole, ora para os interesses das elites locais. Somos um país sem povo, sem voz, sem saberes, sem senões. $O$ ponto a se destacar aqui (ao menos um deles) é que reproduzimos em nossa compreensão da história a mesma dinâmica unilinear e teleológica que o Euronorte reproduz em torno de si mesmo, um continuum, desprezando as omissões históricas e salientando-se as implicações políticas que isso venha a causar. Em larga medida, não é uma questão mais de "como chegamos aqui?", que pressupõe um tempo unilinear e um aqui, enquanto lugar, unívoco. Mas nossa história não é somente teleológica: em que medida realmente crermos que haja um aqui/agora unívoco (e moderno, e masculino, e branco, e classe média) nos legitimar não apenas esse devir histórico mas também a ordem social da forma como se encontra?

A colonialidade nos desafia a repensarmos a história em outros termos mas, além disso, outros termos da história (historicidades-outras, 
temporalidades-outras, memórias-outras,...): a sair da caixa (do "mundo de Truman", referido por Mignolo) e pensar que outras historicidades e afetos findam por ser obscurecidas por nossa visão pretensamente objetiva, neutra e universalizante. Não apenas rever os velhos fatos sob novas roupagens, mas uma ruptura transepistêmica que visibilize as várias zonas de interstício invisibilizadas pelos processos coloniais ainda hoje em marcha. Não uma história relativa, ou relativista, mas relacional e reativa.

\section{Subindo (ou descendo?) as escadas rolantes do shopping}

A imposição de uma forma de ver o mundo, colonizada e pretensamente objetiva e neutra, não apenas justifica a exploração e suplantação de subjetividades-outras: as invisibiliza político-epistemicamente. Afinal, o que querem as periferias ao contraporem projetos e discursos de modernização, desenvolvimento - e, consequentemente, de proletarização e coisificação? Nesse sentido, empreendimentos voltados para a modernidade cumprem interesses de determinados grupos econômicos e políticos que certamente não são os diversos grupos afetados por suas construções. Aí entra a nuvem discursiva desde a qual a colonização é um imenso favor ao colonizado, a fim de livrá-lo do amargo julgo de ser ele mesmo. Civilização não é apenas parte fundamental da imagem que o ocidente tem de si mesmo, mas a justificativa fundamental para que esse complexo autorrepresentacional exista: se há uma razão de ser para o empreendimento colonial, é a perspectiva de que sua existência se confunda com valores pretensamente universais e universalizantes, como democracia, liberdade e liberalismo. Os fins justificam os meios, como se as ações por trás do colonialismo não fossem motivadas pela própria manutenção de seu status quo. Ao colonizado o colonialismo serve como um amargo remédio que, na verdade, virá a matar o paciente. A que custo e preço a manutenção desse sistema se faz cotidianamente?

O que as reações frente às escadas rolantes deste shopping nos dizem sobre o lugar que as cotidianização das técnicas da colonização ocupam nas representações que os colonizados têm de si? De seus aspectos éticos, afetivos, estéticos? De como os subtextos e contextos desses objetos, por meio de uma desconstrução sociológica, interferem no campo das subjetividades, objetivamente falando. Fala-se aqui em escadas, mas se poderia falar em telefones celulares, tablets, computadores e carros de determinadas marcas, vestuários e gadgets de grifes, tanto quanto da cor, da raça, do sexo, dos sotaques, corpos, desejos... Fato é que este espaço de compras e consumo se sobrepõe a um espaço anterior 
de sociabilidades, afetos, cheiros e gostos ${ }^{13}$ completamente diferente, impondo novos padrões estéticos, subjetivos e econômicos por meio dos quais o colonizado, ao seu reinventar, se desinventa. Não estou dizendo que a escada rolante cause isso, ou mesmo os fast foods, blockbusters etc. O que afirmo, contudo, é que a sensação de estranhamento por não dominar determinado capital social e simbólico associado à modernidade causa, no subalternizado, uma sensação de não-pertencimento e de inferiorização que é epidermizado e introjetado. $\mathrm{O}$ objetivo do colonizado passa a ser tornar-se parte da paisagem, uniformizar-se e homogeneizar-se: tornar-se manada. Chamar esses processos de normalização, tendo em mente autores Ocidentais, pura e simplesmente, é perder todo esse feixe de processos que perpassam corpos, afetos, classe, raça, sotaques, estética, cheiros...

Indo mais além - e retomando o espírito das primeiras páginas deste ensaio - nosso desafio é, desde e para a "margens", buscar alternativas nas quais sejamos os protagonistas, sem replicarmos, pura e simplesmente, determinados modelos de análise. Sim, admito que haja uma série de críticas a vários dos autores e conceitos apresentados aqui, mas eles nos instigam a pensarmos fora dos nossos gabinetes, dos CTR+C CTR+V da vida, da reprodução, da bajulação, das zonas de conforto, das análises "objetivas e neutras", da apolítica, do desposicionamento, dos lugares de fala externos e exteriores, da subserviência ao status quo, do assujeitamento, da obscuridade, do conformismo... O ponto - ou um deles - é que este modo confortável de ver/estar/ser no mundo não leva em consideração, justamente, as contrariedades que sustentam a divisão internacional do trabalho científico, das desigualdades sociais, das violências nem sempre tão simbólicas assim,... Um queer caboclo não se restringe, assim, à Amazônia: ela abrange latinidades, periferias, pontos de ônibus e terminais onde nós, os não-ocidentais, sociabilizamos e existimos, teimosamente.

A nós, afinal, não interessa uma práxis epistemopolítica moderno-liberal, bem-comportada, ensimesmada, ensebada e alheia a si mesma. Uma dinâmica de produção de conhecimento operando como shopping centers, nas quais ferramentas teóricas e autores tornam-se nossas próprias escadas rolantes. Tornamo-nos manada, e, no processo, voltamos as costas para as consequências políticas de nosso próprio silêncio. Perdidos nos cocktails acadêmicos e nos rapapés catedráticos, optamos por nos esvaziarmos de nós mesmos, tornando-nos tão insípidos e insossos quanto os big sanduíches. Trata-se de, como

13 A título de provocação, espero sinceramente que algum dia alguém escreva sobre como a colonização opera, também, ao nível dos sentidos, impondo novos padrões de cheiros, gostos, sabores, tatos e escutas. 
apontei anteriormente, de nos descentrarmos e de não nos deixarmos, por mais contraditório que isso soe, nos deixar colonizar por teorias que falam muito de nós, mas por meio de outros (ou de nós como outros).

\section{Referências}

ANZALDÚA, Gloria. Borderlands/La Frontera: The New Mestiza. San Francisco, Aunt Lute Books, 1987.

BALLESTRIN, Luciana. América Latina e o Giro Descolonial. Revista Brasileira de Ciência Política, n. 11, Maio-Agosto de 2013, pp. 89-117.

CASTRO-GÓMEZ, Santiago. La poscolonialidad explicada a los niños. Bogotá, Universidad del Cauca, Instituto Pensar, 2005.

DUSSEL, Enrique. 1492: O encobrimento do outro: a origem do mito da modernidade conferências de Frankfurt. Petrópolis, Vozes, 1993.

FERNANDES, Estevão Rafael. Ativismo Homossexual Indígena: Uma Análise Comparativa entre Brasil e América do Norte. Dados. v. 58, 2015, pp. 257-294.

FERNANDES, Estevão Rafael; GONTIJO, Fabiano de Souza. Diversidade sexual e de gênero e novos descentramentos: um manifesto queer caboclo. Amazônica - Revista de Antropologia, v. 8, n. 1, Julho 2017, pp. 14-22.

GROSFOGUEL, Ramón; MIGNOLO, Walter. Intervenciones Descoloniales: una breve introducción. Tabula Rasa, n. 9, 2008, pp. 29-38.

KUHN, Thomas. A estrutura das revoluções científicas. São Paulo, Editora Perspectiva, 1997.

MARTINS, Paulo Henrique. La Sociología y el espejo de la colonialidad en América Latina. Revista Horizontes Sociológicos, v. 1, 2013, pp. 33-46.

MIGNOLO, Walter. Desobediencia epistémica: retórica de la modernidad, lógica de la colonialidad y gramática de la descolonialidad. Argentina, Ediciones del signo, 2010. MIGNOLO, Walter. Local Histories/Global Designs: Coloniality, Subaltern Knowledges and Border Thinking. Princeton, Princeton University Press, 1999.

Delinking, The Rhetoric of modernity, the logic of coloniality and the grammar of de-coloniality. Cultural Studies, v. 21, n. 2, March 2007, pp. 449-514.

. La opción de-colonial: desprendimiento y apertura. Un manifiesto y un caso. Tabula Rasa. Colômbia, n. 8, enero-junio, 2008a, pp. 243-281.

The Geopolitics of Knowledge and the Colonial Difference. In: MORAÑA, Mabel; DUSSEL, Enrique; JÁUREGUI, Carlos (Eds.) Coloniality at Large. Latin America and the Postcolonial Debate, Latin America Otherwise. Durham, Duke University Press, 2008b, pp. 225-258.

. Desobediência epistêmica: A opção descolonial e o significado de identidade em política. Cadernos de letras da UFF, n. 34, 2008c, pp. 287-324. 
MIGNOLO, Walter; TLOSTANOVA, Madina. The Logic of Coloniality and the Limits of Postcoloniality. In: HAWLEY, John; KRISHNASWAMY, Revathi (Eds.) The Postcolonial and the Global. Minneapolis, University of Minnessota Press, 2008.

MISKOLCI, Richard. A Teoria Queer e a Sociologia: o desafio de uma analítica da normalização. Sociologias, n. 21, 2009, pp. 150-182.

PEREIRA, Pedro Paulo Gomes. A teoria queer e a Reinvenção do corpo. Cad. Pagu. n. 27, 2006, pp. 469-477.

PÉREZ, Emma. The decolonial Imaginary: writing Chicanas into history, Bloomington: Indiana University Press, 1999.

QUIJANO, Aníbal. Colonialidad y modernidad/racionalidad. In: BONILLA, Héctor (Org.) Los conquistados. 1492 y la población indígena de las Américas, Quito, Tercer Mundo -Libri Mundi Editores, 1992.

. Colonialidad del poder y clasificación social. In: CASTRO-GÓMEZ, Santiago; GROSFOGUEL, Ramón (Org.). El giro decolonial. Reflexiones para una diversidad epistémica más allá del capitalismo global, Bogotá, Universidad Javeriana-Instituto Pensar, Universidad Central-IESCO, Siglo del Hombre Editores, 2007, pp. 93-126.

SALIH, Sara. Judith Butler e a Teoria Queer. Belo Horizonte, Autêntica Editora, 2012. TLOSTANOVA, Madina; MIGNOLO, Walter. Learning to Unlearn: Decolonial reflections from Eurasia and the Americas, Columbus, Ohio State University, 2012.

VELHO, Otávio. O que nos une. Anuário Antropológico/2009, Separata, 2, 2010, pp. 9-21.

Recebido em: 20/03/2020

Aprovado em: 23/05/2020

\section{Como citar este artigo:}

FERNANDES, Estevão Rafael. Queer caboclo como possibilidade anticolonial: Algumas reflexões à guisa de provocação. Contemporânea - Revista de Sociologia da UFSCar, v. 10, n. 1, jan.- abril 2020, pp. 35-56. 